\title{
Silica, compensated silicosis, and lung cancer in Western Australian goldminers
}

\author{
Nicholas H de Klerk, A William Musk
}

\begin{abstract}
Objectives-Silica has recently been reclassified as carcinogenic to humans based largely on the observed increase in rates of lung cancer in subjects with silicosis. Other recent reviews have arrived at different conclusions as to whether silicosis or silica itself is carcinogenic. This study aims to examine exposure-response relations between exposure to silica and subsequent silicosis and lung cancer in a cohort of goldminers. Methods-2297 goldminers from Kalgoorlie in Western Australia were examined in 1961, 1974, and 1975. Data were collected on respiratory symptoms, smoking habits, and employment history. Subjects were followed up to the end of 1993. Survival analyses for lung cancer mortality and incidence of compensated silicosis were performed with age and year matched
\end{abstract} conditional logistic regression analyses. Results- $89 \%$ of the cohort were traced to the end of $1993.84 \%$ of the men had smoked at some time and $66 \%$ were current smokers. 1386 deaths occurred during the follow up period, 138 from lung cancer, and 631 subjects were compensated for silicosis. A strong effect of smoking on mortality from lung cancer, and a smaller effect on the incidence of compensated silicosis was found. There was a strong effect of duration and intensity of exposure on the incidence of silicosis. The risk of mortality from lung cancer increased after compensation for silicosis. Of all direct measures of exposure to silica, only log cumulative exposure was significantly related to incidence of lung cancer, but this effect disappeared once the onset of silicosis was taken into account.

Conclusions-The incidence of silicosis was clearly related to exposure to silica and the onset of silicosis conferred a significant increase in risk for subsequent lung cancer, but there was no evidence that exposure to silica caused lung cancer in the absence of silicosis.

(Occup Environ Med 1998;55:243-248)

Keywords: silicosis; lung cancer; goldminers

The International Agency for Research on Cancer has recently reclassified crystalline silica inhaled in the form of quartz or cristobalite from occupational sources as carcinogenic to humans (class 1), although full details of the reasoning behind this decision are not yet available. Previously the conclusion was that silica was carcinogenic to animals and probably carcinogenic to humans (class $2 \mathrm{~A}-$ that is, limited evidence, credible but could be explained by chance, bias, or confounding). ${ }^{1}$

It is well known that people with silicosis die from lung cancer (and other diseases, including tuberculosis) at a higher rate than similar people without silicosis. Some studies have also indicated that increasing exposure to silica increases the risk of lung cancer irrespective of silicosis. $^{2}$ The explanations put forward for these observations have been that ${ }^{3}{ }^{4}:$ (a) fibrosis of silicosis causes cancer as is seen in idiopathic pulmonary fibrosis and possibly also asbestosis; (b) silica (possibly only in its freshly cleaved state $^{4}$ ) is a true carcinogen and that this is shown more easily in subjects with silicosis because silicosis more accurately reflects individual exposure than does duration of employment or estimates of dust exposure measured with standard industrial hygiene methods; $(c)$ because of difficulties in, and lack of reliability of, the diagnosis of silicosis, and because cigarettes may predispose to silicosis and also cause lung cancer, then many subjects diagnosed with silicosis may actually already have lung cancer or the cancer process has already been initiated; (d) because of personal unknown host factors, people who are prone to contracting silicosis are also independently more prone to contracting lung cancer.

Apart from the review by the IARC working party, there have been three extensive fairly recent reviews of this topic which have reached contrasting conclusions. ${ }^{356}$ The first, by Goldsmith, ${ }^{3}$ concluded that silica is a true carcinogen. The other two ${ }^{56}$ concluded that more evidence was required before any of these four explanations could be satisfied.

The cohort of 2297 Kalgoorlie goldminers was established from surveys of respiratory symptoms, smoking, and lung function performed in 1961, 1974, and 1975. An initial analysis from the cohort indicated excess rates of lung cancer although it was considered that these may have been due to smoking ${ }^{7}$ and further analyses showed that these excess rates were restricted to those subjects with more than 40 years of underground work. ${ }^{8}$ Among more recently employed goldminers it has also been shown that exposure to silica was significantly related to bronchitis and airflow obstruction $^{9}$ and also to measures of lung parenchymal function. ${ }^{10}$ Abnormalities on chest $x$ ray film indicative of silicosis were also shown to be associated with both exposure to silica and smoking history. ${ }^{11}$

The aims of the present study were: $(a)$ to extend the follow up on the original cohort, 
Table 1 Ranking of exposure for different jobs: some common jobs and their exposure scores

\begin{tabular}{ll}
\hline Exposure score & Fob titles \\
\hline 1 & Storeman, electrician, prospector \\
2 & Fitter, turner, plant operator \\
3 & Braceman, welder, surveyor \\
4 & Shift boss, skipman, diamond driller \\
5 & Grizzly, running ore passes, long hole driller \\
6 & Timberman, timber boss, crushing plant fitter \\
7 & Locomotive driver, sampler, scraper driver \\
8 & Stoping, bogging, machine mining \\
9 & Development, shaft sinking, rising \\
10 & Winze sinking, winzing
\end{tabular}

adding in 328 men surveyed in a later survey in 1974-5, from 1991 to 1993 and to search for deaths before 1969; (b) to incorporate complete work histories available from records held at the Perth Chest Clinic which has been responsible for mandatory $x$ ray film surveillance of people in the mining industry in Western Australia; (c) to incorporate semiquantitative measures of dust exposure $(d)$ to explore the link between silicosis and lung cancer, and (e) to establish if there is an increased risk of lung cancer in goldminers exposed to silica in Kalgoorlie that is associated with degree of exposure, smoking, and pre-existing bronchitis even in the absence of silicosis.

\section{Subjects and methods} SUBJECTS

One thousand nine hundred and sixty nine subjects who participated in a survey of respiratory symptoms and lung function in Kalgoorlie between 1961 and 1962 were included in the study. To this cohort were added 328 men surveyed in a later survey in 1974-5. The exact response rate was not possible to calculate because the denominator was never accurately known but, based on estimates of the workforce at each time, it is thought that over $95 \%$ response was achieved. ${ }^{12}$

Table 2 Demographic and exposure data

\begin{tabular}{|c|c|c|}
\hline Age at survey (median (range)) & 49 & $16-75$ \\
\hline \multicolumn{3}{|c|}{ Months of employment in goldmining (median (range)): } \\
\hline Underground & 192 & $0-594$ \\
\hline Surface & 50 & $0-586$ \\
\hline \multicolumn{3}{|c|}{ Exposure intensity score (1-10 increasing) (median (range)):* } \\
\hline Underground & 5.0 & $0-10$ \\
\hline Surface & 1.5 & $0-8$ \\
\hline \multicolumn{3}{|l|}{ Smoking habit (n (\%)): } \\
\hline Never & 353 & 15 \\
\hline $\mathrm{Ex}$ & 359 & 16 \\
\hline \multicolumn{3}{|l|}{ Current (cigarettes/day): } \\
\hline $1-14$ & 433 & 19 \\
\hline $15-24$ & 756 & 33 \\
\hline$\geqslant 25$ & 343 & 15 \\
\hline Pipe or cigar & 49 & 2 \\
\hline Compensated for silicosis (n (\%)) & 662 & 29 \\
\hline Bronchitis at survey (n (\%)) & 1110 & 48 \\
\hline \multicolumn{3}{|l|}{ Period of first employment (n (\%)) } \\
\hline$<1920$ & 200 & 9 \\
\hline $1920-29$ & 560 & 24 \\
\hline $1930-39$ & 382 & 17 \\
\hline $1940-49$ & 646 & 28 \\
\hline $1950-59$ & 324 & 14 \\
\hline $1960+$ & 185 & 8 \\
\hline \multicolumn{3}{|l|}{ Place of birth (n (\%)): } \\
\hline Australia & 1661 & 72 \\
\hline British Isles & 348 & 15 \\
\hline Balkans & 99 & 4 \\
\hline Elsewhere & 189 & 9 \\
\hline
\end{tabular}

${ }^{\star} 0=$ Never worked in that location.
METHODS

Data collection

Initial survey-Records from the surveys held on microfiche were abstracted to provide name, sex, date of birth, height, job description, time spent at work, and smoking history. The survey also included a slightly modified British Medical Research Council questionnaire on respiratory symptoms. Bronchitis was defined as cough or phlegm for greater than three months in a year for two years or more. All this information was stored on computer and used to match to the other sources of data.

Employment history-Employment history up to the time of the survey was recorded in the initial survey. Full employment details had also been recorded on the miners' record cards held at the Perth Chest Clinic. These include details of dates of employment at each mine and job description, as well as other clinical information, which had been recorded each time a subject returned for compulsory annual chest $x$ ray films as long as he continued work as a miner. These records were found to be much more detailed than the survey employment histories and were therefore used to provide each subject's full employment history in the goldfields.

Vital status and disease follow up-Some information on vital status and disease, including dates and amounts of compensation for silicosis were also obtained from the miners' record cards at the Perth Chest Clinic. Compensation for silicosis was awarded by the Pneumoconiosis Medical Board (previously the Miners Phthisis Control Board) and was based on a combination of signs on chest $x$ ray films and other symptoms. The Board included a changing panel of occupational and respiratory physicians who made a consensus diagnosis and awarded a notional fractional disability level. The criteria for making the award will have altered considerably over the 33 years that this study covers, but comprised whatever generally accepted criteria were in operation at that time.

All subjects were matched, by computerised record linkage, ${ }^{13}$ to all Western Australian deaths registered at the Registrar General's Department from 1969 to 1993. Those not found were then searched for on the Western Australian electoral roll, the Western Australian Cancer Registry, and written records of deaths from 1961 to 1968 at the Western Australian Registrar General's Office.

\section{EXPOSURE ASSESSMENT}

Although detailed measurements of dust counts have been made in Kalgoorlie goldmines since 1925, it seems that the original data sheets for measurements up to 1976 were destroyed. Annual average counts were estimated by Hewson ${ }^{12}$ but included all mines and so were not detailed enough. For this report the following approximate procedure was used.

A panel of experts including several former mines inspectors, industrial hygienists, occupational physicians, and public health practitioners, was convened to make a subjective ranking (on a scale of 1 to 10 of increasing dust levels) 
Table 3 Principal causes of death 1961-93

\begin{tabular}{lr}
\hline Lung cancer & 138 \\
All other cancers & 173 \\
Pneumoconiosis & 48 \\
Chronic obstructive lung disease & 99 \\
Ischaemic heart disease & 475 \\
Other circulatory disease & 228 \\
Digestive diseases & 27 \\
Accidents, poisoning, and violence & 68 \\
Other causes & 130 \\
Total deaths & 1386 \\
\hline
\end{tabular}

of every job that any of the men had done. Consensus rankings were made specific for each calendar period where the panel thought that changes in engineering procedures and controls would have led to changes in dust levels. This list of exposure scores was compiled and then reverified by one of the mines inspectors. Semiquantitative estimates of average and cumulative exposure to silica were then made, separately for underground and surface exposure, by combination of the assigned exposure scores and the employment records of each person. Table 1 shows the exposure scores to some typical jobs.

STATISTICAL METHODS

The standardised mortality ratio (SMR) was calculated from the ratio of observed deaths to expected deaths for all causes, lung cancer (primary malignant tumours of the trachea, bronchus, and lung) and pneumoconiosis (due to silica and silicates). Expected numbers of deaths in the cohort were calculated by the person-years method ${ }^{14}$ by use of age, calendar period, cause, and sex specific death rates for Western Australia. We calculated these rates from annual tabulations of deaths prepared by the Australian Bureau of Statistics. The calendar periods adopted, usually of five years duration, were also designed to begin or end with years of change from one revision of the ICD to the next, starting from 1961.

For this study, as elsewhere, ${ }^{15}$ the numbers of person-years for estimating expected deaths were counted in two ways: firstly, assuming that all subjects who were lost to follow up were still alive on 31 December 1993 or were censored at the age of 85 years, whichever was earlier, yielding SMR1, and secondly, after censoring

Table 4 Associations between incidence of silicosis and employment variables, smoking, and bronchitis *

\begin{tabular}{lll}
\hline Variable & Relative rate & 95\% CI \\
\hline Smoking habit: & & \\
$\quad$ Non-smoker & 1.00 & \\
Ex-smoker & 1.40 & 1.01 to 1.96 \\
$\quad$ Current 1-14 & 1.73 & 1.24 to 2.40 \\
Current 15-24 & 1.73 & 1.28 to 2.35 \\
Current $\geqslant 25$ & 2.02 & 1.44 to 2.92 \\
$\quad$ Pipe or cigar & 1.92 & 1.11 to 3.33 \\
Years from first employment: & & \\
$\quad<30$ & 1.0 & \\
30-39 & 1.38 & 1.07 to 1.80 \\
40-49 & 1.94 & 1.48 to 2.54 \\
$\quad \geqslant 50$ & 1.49 & 1.01 to 2.19 \\
Duration of underground employment (log (month)) & 1.96 & 1.65 to 2.34 \\
Intensity of underground exposure (unit rank) & 1.24 & 1.18 to 1.30 \\
Duration of surface employment (log (month)) & 1.58 & 1.31 to 1.91 \\
Duration of surface employment (underground workers) (log & & \\
$\quad$ (month)) & 0.61 & 0.52 to 0.72 \\
Bronchitis at survey & 1.28 & 1.07 to 1.53 \\
\hline
\end{tabular}

^All variables included together in one model. all subjects at the date they were last known to be alive, yielding SMR2. These two estimates of SMR provide lower (SMR1) and upper (SMR2) estimates of the true SMR. ${ }^{16}{ }^{17}$

Cases of lung cancer were matched to all subjects from the cohort who were not known to have developed cancer of this site by the year of death of the case, who were the same age, and who were known to be alive at the time of diagnosis of the case. Subjects could be controls for more than one case and cases could be controls in years before the onset of their disease.

Variables compared between cases and controls were smoking status, duration of underground and surface employment, cumulative exposure to silica (calculated as the sum of the products of the time and dust concentration expressed as the 1-10 exposure score already defined for each job), time weighted average of estimated silica dust concentration (cumulative exposure divided by the total duration of employment), time since first exposure (years), decade of first employment, and work site (underground only, underground and surface, surface only). Apart from decade of first employment, all these variables were time dependent and considered only up to the time of the death of the case. Continuous variables were also categorised to examine non-linearity of effects. Because the effect of the incidence of silicosis might vary with time, the effect of years from onset of silicosis was also estimated. Subjects yet to be compensated for silicosis were considered to be free of the disease. Because of possible changes in diagnostic criteria for silicosis over time, the effect of silicosis diagnosis was also examined separately for different decades of diagnosis.

Smoking habit was categorised as that given at the time of survey and was assumed not to change throughout the study. Presence of bronchitis at the survey as already defined was also included as a covariate.

The frequencies of the variables of interest in the matched sets of cases and controls were compared by conditional logistic regression analysis with the Cox regression program from SPSS for Windows ${ }^{18}$ stratified on combined values of year of birth and year at risk with a constant survival time variable.

Table 2 shows the variables that were modelled individually and where relevant, together, and basic categorisations. Most exposure variables were also modelled continuously and the fits of these models were compared with their categorised counterparts only by comparison of the residual deviance which approximates to a $\chi^{2}$ distribution. ${ }^{19}$

Apart from not including incidence of silicosis as a covariate, the analysis plan and strategy for silicosis was exactly as already described for lung cancer. Because of the matching on year of birth and year of disease, the effects of time from first exposure and decade of first starting could not be examined at the same time and were modelled separately. Similarly, possible effects of decade of diagnosis of silicosis could only be examined in terms of the interaction with exposure. Coincidentally, numbers of 
Table 5 Associations between smoking, other disease, and lung cancer ${ }^{\star}$

\begin{tabular}{lcl}
\hline & Relative rate & $95 \%$ CI \\
\hline $\begin{array}{l}\text { Smoking habit: } \\
\quad \text { Never }\end{array}$ & 1 & - \\
Ex & 10.7 & 1.4 to 81.9 \\
$\quad$ Current (cigarettes/day): & & \\
$\quad 1-14$ & 19.4 & 2.6 to 143.7 \\
$\quad 15-24$ & 23.0 & 3.2 to 167.6 \\
$\quad \geqslant 25$ & 32.5 & 4.4 to 241.2 \\
$\quad$ Pipe or cigar only & 9.1 & 0.82 to 101.1 \\
Silicosis (after diagnosis) & 1.59 & 1.10 to 2.28 \\
Bronchitis (at survey) & 1.60 & 1.09 to 2.33 \\
\hline
\end{tabular}

*All variables included together in one model.

controls per case for both outcomes varied from one to 87.

Analyses were done with and without 35 subjects who were known to have also worked with asbestos. Nickel mines began operation in the Kalgoorlie area in 1966 and rapidly expanded. For the purposes of this study, duration of underground and surface work in nickel mines was included with goldmining exposure, but a variable indicating work in nickel mines was also included in analyses to estimate possibly differing effects. A few subjects had worked for short periods in mining other minerals, such as coal, copper, manganese, etc, these periods were excluded from their total exposure. The possibility of exposure to radon in underground mines has been explored before and the amounts were found to be negligible ${ }^{2021}$; we therefore ignored radon for this study.

\section{Results}

Forty six per cent of subjects had bronchitis at the time of survey and $15 \%$ had never smoked. Duration of employment ranged from none to about 50 years underground and about the same on the surface (table 2). Twenty subjects had started work before 1910 but most started in the 1940 s. About $72 \%$ of the workforce were Australian born with a further $14 \%$ being born in the United Kingdom.

FOLLOW UP AND VITAL STATUS OF COHORT

More than half the cohort had died (table 3 ) and a further 654 were still alive, leaving 257 (11\%) untraced on 31 December 1993. Of these 257,222 had some follow up after the survey and 118 had some follow up after ending employment. Assuming cases lost to follow up lived to age 85 or 31 December 1993, whichever was earlier, there were 49767 person-years of follow up from the date of first survey. Counting only follow up to the date last known to be alive, the total follow up time was 45117 person-years.
Assuming that all subjects who were lost to follow up were still alive up to 31 December 1993 or to the age of 85 years, the SMR for death from all causes was 1.00 (95\% CI 0.95 to 1.05). The SMR for lung cancer was significantly increased $(1.26,95 \%$ CI 1.07 to 1.59$)$ when compared with the age, sex, and period matched Western Australian population, as was the SMR for pneumoconiosis $(9.5,95 \%$ CI 7.2 to 12.7). After censoring all subjects at the date they were last known to be alive, the SMR for all causes was 1.23 (95\% CI 1.17 to 1.30 ), for lung cancer it was 1.49 (95\% CI 1.26 to 1.76 ), and for pneumoconiosis it was 11.2 (95\% CI 8.4 to 14.8 ).

\section{INCIDENCE OF SILICOSIS}

One thousand and forty subjects applied for pneumoconiosis compensation at least once during the follow up period and 631 were compensated. A further 31 had already received some compensation at the time of their first survey and were ignored in these analyses of incidence. Smoking had a consistent and significant effect on the incidence of silicosis (table 4). Risk of silicosis increased with duration of underground exposure and less so with duration of surface exposure. For subjects who worked both underground and on the surface, duration of surface exposure was significantly protective - that is, people who worked both underground and on the surface had a slight decrease in relative risk of silicosis of $(1.58 \times$ $0.61)=0.96$ per $\log$ month of their surface employment. The effect of intensity of exposure to silica (as expressed per rank score of job level of exposure) was also strong and there was a steady decline of risk with decade of first employment. A marginally better fit was obtained with time from first exposure rather than decade of first exposure, the peak incidence occurring about 45 years after first exposure. After accounting for effects of work exposure, there was also an additional effect of the presence of bronchitis at survey on the risk of silicosis. Average intensity of surface exposure as assessed by the ranked exposure scores had no significant effect on the incidence of silicosis, although total cumulative exposure (adding the product of durations of all jobs, whether underground or surface, and their respective exposure scores) was a better fit to the data than just cumulative underground exposure. There was no significant $(p<0.15)$ interaction of either duration or intensity of exposure with decade of first employment, year of diagnosis, or time from first exposure.

Table 6 Associations between silica exposure variables and lung cancer mortality after adjustment for smoking and bronchitis only *

\begin{tabular}{llll}
\hline Variable & Units & Relative rate & 95\% CI \\
\hline Total cumulative exposure & Exposure-score year & 1.003 & 0.999 to 1.005 \\
& Log (exposure-score year) & 1.31 & 1.01 to 1.70 \\
Duration of underground employment & Log (month) & 1.06 & 0.97 to 1.15 \\
Intensity of underground exposure & Exposure score & 1.02 & 0.96 to 1.08 \\
Duration of surface employment & Log (month) & 1.02 & 0.94 to 1.09 \\
Intensity of surface exposure & Exposure score & 1.04 & 0.93 to 1.16 \\
\hline
\end{tabular}

^Each variable added separately to a model including smoking and bronchitis only. 
Table 7 Associations between silica exposure variables and lung cancer mortality after adjustment for smoking, bronchitis, and occurrence of silicosis *

\begin{tabular}{llll}
\hline Variable & Units & Relative rate & $95 \%$ CI \\
\hline Total cumulative exposure & Exposure-score year & 1.00 & 0.998 to 1.004 \\
& Log (exposure-score year) & 1.20 & 0.92 to 1.56 \\
Duration of underground employment & Log (month) & 1.02 & 0.92 to 1.12 \\
Intensity of underground exposure & Exposure score & 0.98 & 0.92 to 1.05 \\
Duration of surface employment & Log (month) & 1.05 & 0.97 to 1.14 \\
Intensity of surface exposure & Exposure score & 1.05 & 0.95 to 1.17 \\
\hline
\end{tabular}

^Each variable added separately to a model including smoking, bronchitis, and silicosis.

MORTALITY FROM LUNG CANCER

There was a very strong effect of smoking on risk of lung cancer (table 5), with only one case reported as never smoking. The effect of diagnosis of silicosis decayed slightly with time from diagnosis, but not significantly so. The strongest effect was obtained $0-1$ years after compensation. There was also an effect of the presence of questionnaire diagnosed bronchitis at the survey on mortality from lung cancer, as well as the effects of both smoking and silicosis. Of all direct measures of exposure to silica, only log cumulative exposure was significantly related to incidence of lung cancer (table 6), but this effect decreased to insignificance once the onset of silicosis was taken into account (table 7), although the effect was still positive. There was no significant $(\mathrm{p}<0.15)$ effect of any other variables of exposure to silica on lung cancer and no significant interaction of smoking with either silicosis or bronchitis.

\section{Discussion}

This study of a cross sectionally defined cohort of goldminers has shown significantly increased mortalities from lung cancer and pneumoconiosis when compared with the rest of the Western Australian population.

The incidence of silicosis was significantly related to both duration and intensity of exposure to dust. Duration of surface exposure also conferred additional risk of disease. The incidence also declined steadily with decade of first employment in goldmining but although this effect may be due to the effect of dust suppression measures in the industry, it seemed to be more strongly related to the effect of time from first exposure on incidence of disease.

The ranking process for jobs used in this study seems to have external validity given the association of exposure with incidence of silicosis. These ordered, but not precisely quantified, exposure scores were shown to have external validity in that they were associated both with the incidence of compensated silicosis and also with the prevalence of bronchitis (unpublished observations) and can therefore be used in further studies. The lack of a significant interaction of exposure score with decade of employment also gives further support to the validity of these scores.

The increase in lung cancer mortality in this cohort was restricted to people who had received compensation for silicosis and this increase seemed to act immediately and constantly after the date of compensation. A possible explanation is that localised immune suppression due to silicosis leads to an increased risk of lung cancer, just as subjects with silicosis are subject to increased risks of other diseases caused by lack of immunocompetence such as Caplan's syndrome, various arthritic diseases, and also tuberculosis. This explanation is slightly different from explanation $(a)$ in the introduction which assumes that it is the byproducts of the inflammatory process in fibrosis that either increase the rate of cell mutation, or the rate of cell proliferation and hence the probability of mutation. Such a process would lead to a risk of lung cancer that would increase steadily with time from the onset of fibrosis. The suggestion postulated here of a comparatively immediate loss in immune capability would lead to a fairly immediate increase in risk of lung cancer which would remain roughly constant, as was actually found here and elsewhere. ${ }^{22}$

If misdiagnosis of silicosis instead of early cancer was the explanation for the association found between silica and lung cancer (explanation (c) from the introduction), then the association of silicosis with lung cancer would be expected to decline with time from the diagnosis of silicosis. It should be noted therefore that a combination of misdiagnosis and cancer caused by the fibrosis of silicosis (explanations (a) and (c) acting together) could cause the same observed result of an apparently immediate and constant increase in risk of lung cancer after silicosis was diagnosed.

In this cohort there was a strong relation between mortality from lung cancer and tobacco smoking and also between smoking and the incidence of compensated silicosis, suggesting that symptoms due to smoking may be increasing the likelihood of a worker making a successful claim for compensation for silicosis and again raising the question of the precise interrelations between smoking, compensation for silicosis, radiographic changes consistent with silicosis, and lung cancer.

The significant effect of smoking on compensation for silicosis indicates that results from studies that ignored smoking may be questionable. Although it is accepted that smoking is unrelated to the onset of simple silicosis, evidence for any possible effects of smoking on progression of silicosis is limited. The associations shown here could also be the result of smokers either being more likely to make a claim because of general debility due to smoking or being more likely to be awarded compensation because of more severe symptoms as well as findings on $x$ ray films.

The results from this study, like others, ${ }^{23}$ cannot definitely confirm the route whereby exposure to silica may result in lung cancer. The lack of a significant effect of exposure once 
silicosis is accounted for could possibly be explained by random error in the exposure measures biasing the estimated effects towards the null, ${ }^{24}$ but the fact that the exposure measures give consistent effects for silicosis and very inconsistent effects for lung cancer makes this explanation unlikely.

Without question, subjects who develop silicosis are more likely to develop lung cancer, and risk of silicosis increases with increasing exposure to silica. Studies from overseas imply that current exposure standards for exposure to crystalline silica in the mining industry that are designed to prevent silicosis are set too high, 25 but these results have not been confirmed by data from Australia. If however current standards are too high it is not clear that currently available testing methods would be adequate at much lower levels, as no readily available dust collection methods exist that could reliably detect a level of, for example, $0.05 \mathrm{mg} / \mathrm{m}^{3}$, so that it would be impossible to verify whether such standards were being maintained..$^{27}$ What is certain, however, is that if exposure is sufficient to cause silicosis then it will be sufficient to increase the risk of lung cancer.

We are grateful to Jim McNulty, Pat Gilroy, Brian Galton-Fenzi, Nic Ormonde, Greg Hewson, Keith Quartermaine, Terry Fisher, Eric Shenton, and Jack McDermott for help with all aspects of exposure assessment and interpretation of work histories and to Ernie Mastromatteo and Geoffrey Berry for helpful comments on an earlier draft. The study could not have been completed without the computing and clerical assistance of Raymond Kan, Jan Eccles, Sylvia Tetlow, Jan Sleith, Toby Leys, Michael Musk, Lily Naumowski, Janice Hansen, and Mines of Western Australia.

1 International Agency for Research on Cancer. IARC monographs of the evaluation of the carcinogenic risk of chemicals to
humans. Vol 42. Silica and some silicates. Lyon: IARC, 1987.

2 Checkoway H, Heyer NJ, Demers PA, et al. Mortality among workers in the diatomaceous earth industry. $B r f$ among workers in the diat

3 Goldsmith DF. Silica exposure and pulmonary cancer. In: Samet JM, ed: Epidemiology of lung cancer. New York: Marcel Dekker, 1994:245-98.

4 Goldsmith DF, Wagner GR, Saffiotti U, et al. Future research needs in the silica, silicosis and cancer field. Scand f Work Environ Health 1995;21(supp 2):115-7.

5 Berry G. Crystalline silica: health impacts and possible lung cancer risks. Fournal of Occupational Health and Safety of Australia and New Zealand 1996;12:157-67.

6 Weill H, McDonald JC. Exposure to crystalline silica and risk of lung cancer; the epidemiological evidence. Thorax 1996;51:97-102.
7 Armstrong BK, McNulty JC, Levitt LJ, et al. Mortality in gold and coal miners in Western Australia with special reference to lung cancer. Br f Ind Med 1979;36:199-205.

8 de Klerk NH, Musk AW, Tetlow S, et al. Preliminary study of lung cancer mortality among Western Australian gold miners exposed to silica. Scand $\mathcal{F}$ Work Environ Health 1995;21 (suppl 2):66-8.

9 Holman CDJ, Psaila-Savona P, Roberts M, et al. DetermiWestern Australian gold miners. Br f Ind Med 1987;44: $810-8$.

10 Musk AW, Rouse IL, Rivera B, et al. Respiratory disease in non-smoking Western Australian goldminers. Br f Ind Med 1992;49:750-4.

11 Musk AW, de Klerk NH, Rouse IL, et al. Duration of underground employment and radiological changes in Western Australian goldminers. In: Hurych J, Lesage M, David A, eds. Proceedings of the 8th International Conference on Occupational Lung Diseases. Prague: Czech Medical Society, 1993:677-82.

12 Hewson GS. Estimates of silica exposure among metalliferous miners in Western Australia (1925-93). Perth: Department of Minerals and Energy of Western Australia, 1993.

13 de Klerk NH, Armstrong BK. Admissions to hospital for road trauma in patients with diabetes mellitus. $\mathcal{F}$ Epidemiol Community Health 1983;37:232-7.

14 Coleman M, Hermon C, Douglas A. Person-years (PYRS): a Fortran program for cohort study analysis. Lyon: International Agency for Research on Cancer, 1989. (IARC Internal Agency for Resear

15 de Klerk NH, Musk AW, Armstrong BK, et al. Diseases in miners and millers of crocidolite from Wittenoom, Western Australia: a further follow-up to December 1986. Ann Occup Hyg 1994;38(suppl 1):647-55.

16 Armstrong BK, de Klerk NH, Musk AW, et al. Mortality in miners and millers of crocidolite in Western Australia. $\mathrm{Br} \mathcal{F}$ Ind Med 1988;45:5-13.

17 Monson RR. Occupational epidemiology. 2nd ed. Boca Raton: CRC Press, 1990:111-2.

18 Norusis MJ. SPSS for windows. Chicago, SPSS, 1993.

19 Breslow NE, Day NE. Statistical methods in cancer research. Vol 2. The design and analysis of cohort studies. Lyon: Vol 2. The design and analysis of cohort studies.

20 Leith IS, Hartley B. Report on a survey of radioactivity in air of underground non-uranium mines and uranium and thorium mills in Western Australia from 19 November to 5 December 1973. Report to the Commissioner of Public Health, Western Australia

21 Hewson GS, Ralph MI. An investigation into radiation exposures in underground non-uranium mines in Western Australia. Perth: Department of Minerals and Energy of Western Australia, 1994.

22 Meijers JMM, Swaen GMH, Slangen JJM. Mortality and lung cancer in ceramic workers in The Netherlandspreliminary results. Am f Ind Med 1996;30:26-30.

23 Hnizdo E, Murray J, Klempman S. Lung cancer in relation to exposure to silica dust, silicosis, and uranium production in South African gold miners. Thorax 1997;52:271-5.

24 de Klerk NH, English DR, Armstrong BK. A review of the effects of random measurement error on relative risk effects of random measurement error on relative risk
estimates in epidemiological studies. Int $\mathfrak{f}$ Epidemiol estimates in epide.

25 Rice FL, Stayner LT. Assessment of silicosis risk for occupational exposure to crystalline silica. Scand $\mathcal{F}$ Work Environ Health 1995;21 (suppl 2):87-90.

26 Steenland K, Brown D. Silicosis among gold miners: exposure-response analyses and risk assessment. Am F Public Health 1995;85:1372-7.

27 Lorbereau CD, Abell MT. Methods used by the United States National Institute for Occupational Safety and
Health to monitor crystalline silica. Scand $\mathcal{f}$ Work Environ Health 1995;21(suppl 2):35-8. 